




\section{A LOW-PRESSURE GLOW-DISCHARGE \\ PROTON SOURCE}

\section{A Thesis}

Submitted in Partial Fulfillment of the Requirements for the Degree of Doctor of Philosophy in the Graduate School of MoGill University.

By

Paul Lorrain

April 1947 
A LOW-PRESSURE GLOV-DISCHARGE PROTON SOURCE By

Paul Lorrain

\begin{abstract}
Summary
A cold cathode proton source and

operating at about 200 volts a pressure of a few microns is described. The discharge is essentially similar to that of a Philips vacuum gauge. The characteristics of the discharge, the ion extraction and the proton production have been investigated. The addition of $10 \%$ of oxygen to the hydrogen increased the proton content of the ion beam from $10 \%$ to $50 \%$ while introducing only about 1\% of oxygen and other foreign ions. The ionization processes are discussed.
\end{abstract}




\section{Contents}

Page

Introduction

I. Apparatus

1. The Vacuum System

2. The Discharge Tube and the

Beam-Forming Lens

3. The Mass-Spectrograph 10

II. Results

1. The Discharge

2. Proton Production

3. Ionization Processes 19

4. Ion Extraction 27

Conclusions

Appendix

Acknow ledgements 38

B1bl10graphy 


\section{INTRODUCTION}

The problem of the positive ion source for ion accelerators, and in particular of the proton source, has been stated by a number of authors $(3,5,11,15,19,31,34$, $39,41,42)$. It will suffice here to enumerate the desirable characteristics for such a source. They are: (a) ion beam current of the order of 1 milliampere or more, depending on the accelerator, beam cross-section of the order of 10 square millimeters, and low angular spread; (b) low energy spread in the ion beam; (c) high percentage of atomic ions; (d) low gas flow from the ion source to the accelerator; (e) small size; (f) possibility of varying the ion beam current independently of the pressure and of the ion beam focusing; ( $g$ ) low power dissipation; (h) stability, simplicity of operation and of power supplies. The relative importance of these characterLstics depends on the accelerator and on the measurements contemplated.

For simplicity of operation, it is important that the source should not require a heated filament because (a) the filament is gradually destroyed by the positive ion bombardment and has a life span at most of the order of 100 hours, and (b) a filament power supply is required. Since the filament of a cyclotron ion source must be operated perpendicularly to a 
high magnetic field, it is usually heated with a high frequency current to reduce the mechanical strain, and the power supply required is very elaborate and expensive. Most positive ion sources require a heated fllament. The high voltage canal-ray tube $(5)$, the F. M. Penning $(30)$ and the T. Franzini sources $(12,13,17)$ are notable exceptions.

The type of discharge used in the present source appears to have been originated by L. R. Maxwell in 1931 (26). In his discharge, the electron path length from cathode to anode, and thus the number of ion pairs produced per electron emitted at the cathode, at low pressure, was multiplied by a large factor through electron oscillations. In this way, a low voltage discharge could be maintained even at very low pressures when the mean free path of the electrons for ionization was much larger than the dimensions of the discharge tube. Fig. 1 shows a schematic diagram of the L. R. Maxwell source.

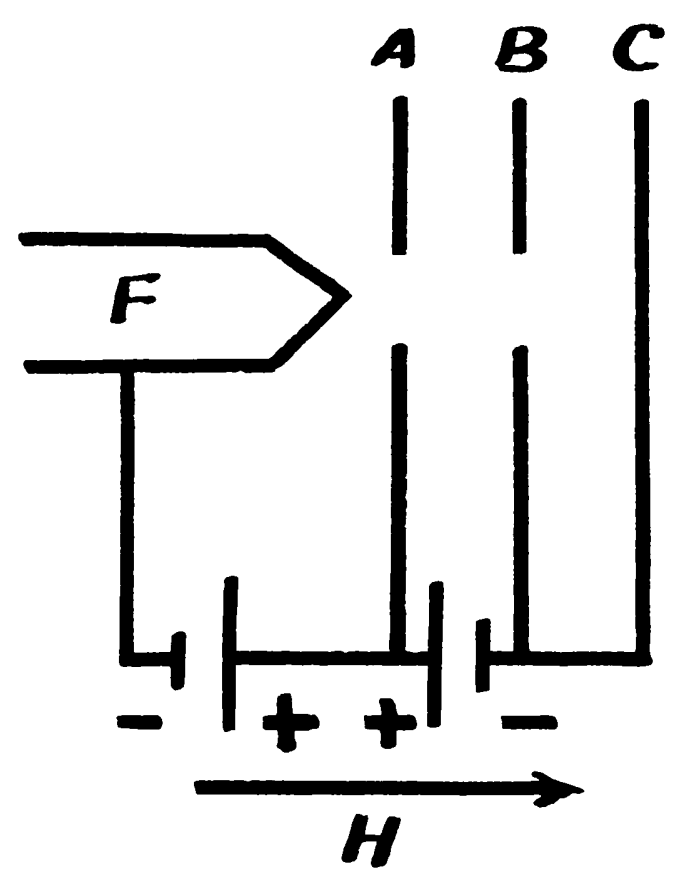

Fig. 1 
A heated filament, $\mathbf{F}$, was used as cathode and a plate, $\mathbf{A}$, pierced with a hole opposite the filament, was used as anode. Parallel to the anode and on the side opposite to that of the filament was a second similar plate, $B$, negative with respect to the anode. The electrons emitted by the filament were focused by a powerful axial magnetic field through the hole in the anode, and reflected back to the filament by the second plate. The electrons were again reflected at the filament and thus described a large number of oscillations before reaching the anode. Positive ions were collected on a third parallel plate, C, through a hole in the second plate, B. This source could produce 3 milliamperes of positive ions at a pressure of 3 microns, which is excellent, even today. It does not seem to have attracted much attention, however, probably because it required a magnetic field of 12,000 gauss and because the ions were collected immediately behind the second plate and were not avallable as a beam. Also, at the time, positive ion sources were of much less interest than they are today.

In 1937, F. M. Penning investigated two different types of low-pressure glow discharges in which electrons were made to oscillate in a magnetic field. One type was the "inverted magnetron" (28). The other was essentially similar to L. R. Maxwell's source, but operated with a cold cathode. Using this latter type, F. M. Penning designed a vacuum gauge, now 
known as the Philips gauge (29), and an ion source (30). The discharge for his ion source occur'ed between three parallel plates, the two outside ones being the cathodes and the center one, with a hole in its center, being the anode. The magnetic field was axial. Electrons were extracted from the cathodes by positive ion bombardment, as in the ordinary glow discharge, and described oscillations between the two cathodes along the magnetic lines of force. The ion beam emerged from a hole in one of the cathodes. F. M. Penning's original paper seems to be the only one in the literature on this type of ion source. The operating voltage and the energy spread of the ion beam were very high, of the order of 10,000 volts.

In 1940, L. P. Smith and A. T. Finklestein (10) designed a source similar to that of Maxwell, but operating at magnetic fields of a few hundred gauss and producing a maximum ion beam current of 150 milliamperes. The operating voltage was low, about 50 volts. This was followed in Germany by a number of similar sources $(15,39,40,41)$, notably those of M. von Ardenne (39, 40).

A. G. Ward, of the Montreal Laboratory of the National Research Council, undertook, in the spring of 1945, the design of a positive ion source of the Penning type for a Van de Graaff accelerator. With brass or steel electrodes, ion beam currents of 3.5 milliamperes were obtained at a pressure of 5 to 10 microns for a discharge current of 10 milliamperes and a discharge voltage of 1 to 2 kilovolts. A later source gave ion 
beams of 100 to 150 microamperes at 1 or 2 microns with 500 microamperes and 5 kilovolts at the discharge. The proton percentage in the ion beam was not investigated. The main difficulties were the rapid variation of the source characteristics with pressure and the apparent existence of widely different modes of operation at a given pressure (42).

During the summer of 1945, the writer investigated the discharge of the Penning source. It was found that the discharge could be made to be completely reliable at pressures above a few microns, and that the discharge voltage could be reduced to 200 volts by using magnesium cathodes. At this low voltage the electrons ionize hydrogen with about their maximum efficiency (27). An all-metal brass and magnesium source, assembled with rubber gaskets and bolts, was designed and used with a $C$ type magnetron magnet. Ions were extracted perpendicularly to the magnetic field. The power dissipation was very low. The "inverted magnetron" was also investigated briefly ( $v$. Appendix) (23).

Simultaneously, E. Gupthill and M. Telford of the cyclotron group at McGill University investigated various modifications of the low voltage discharge with magnesium cathodes in the field of a powerful electromagnet. The discharge was very satisfactory and intense ion beams were produced.

Hydrogen could thus be ionized at low pressure and low voltage in a cold cathode discharge. The preliminary work on the extraction of the ion beam was promising. However, the 
proton production remained to be investigated. In all of the above-mentioned work, total ion beam currents had been measured and only rather doubtful guesses could be made at the actual proton current in the ion beam. M. von Ardenne had stated that the proton content in his ion beams was 50\% (39) but this percentage did not seem to be very reliable, as it could be expected to vary widely with the operating conditions of his source. With the help of a National Research Counc1l Grant for Research awarded to the writer, the equipment described below was constructed in the Physics Department of Laval University and served to investigate the percentage of protons in the ion beam and the fonization processes in the discharge. 


\section{Apparatus}

1. The Vacuum System.

Figs. 2 and $2 a$ show the ion source and the massspectrograph used. A Distillation Products VMF-50 all-metal oil-diffusion pump was used with Dow Corning Silicone Fluid No. 703. The backing pump was a Cenco Megavac. Except for the glass parts shown in Fig. 2, the system was all metal. The pumping speed for air was about 10 litres per second at $P$ and about 0.3 litre per second through the hole in $K_{2}$. Electrolytic hydrogen, supplied in tanks by the Dominion Oxygen Company, Montreal, and containing $99.7 \%$ hydrogen and $0.3 \%$ oxygen, was piped through a clean copper tube and admitted to the system through a needle valve. The pressure in the hydrogen line was kept slightly above the atmospheric pressure to avoid the possible introduction of air. Water and other vapours could be added to the hydrogen by bubbling it in a flask near the needle valve. Hydrogen could be mixed with various percentages of oxygen by collecting the gases over water in an inverted beaker serving as a gasometer. The water was at room temperature. When pure hydrogen was required, the needle valve was replaced by a palladium diffusion tube (18). 


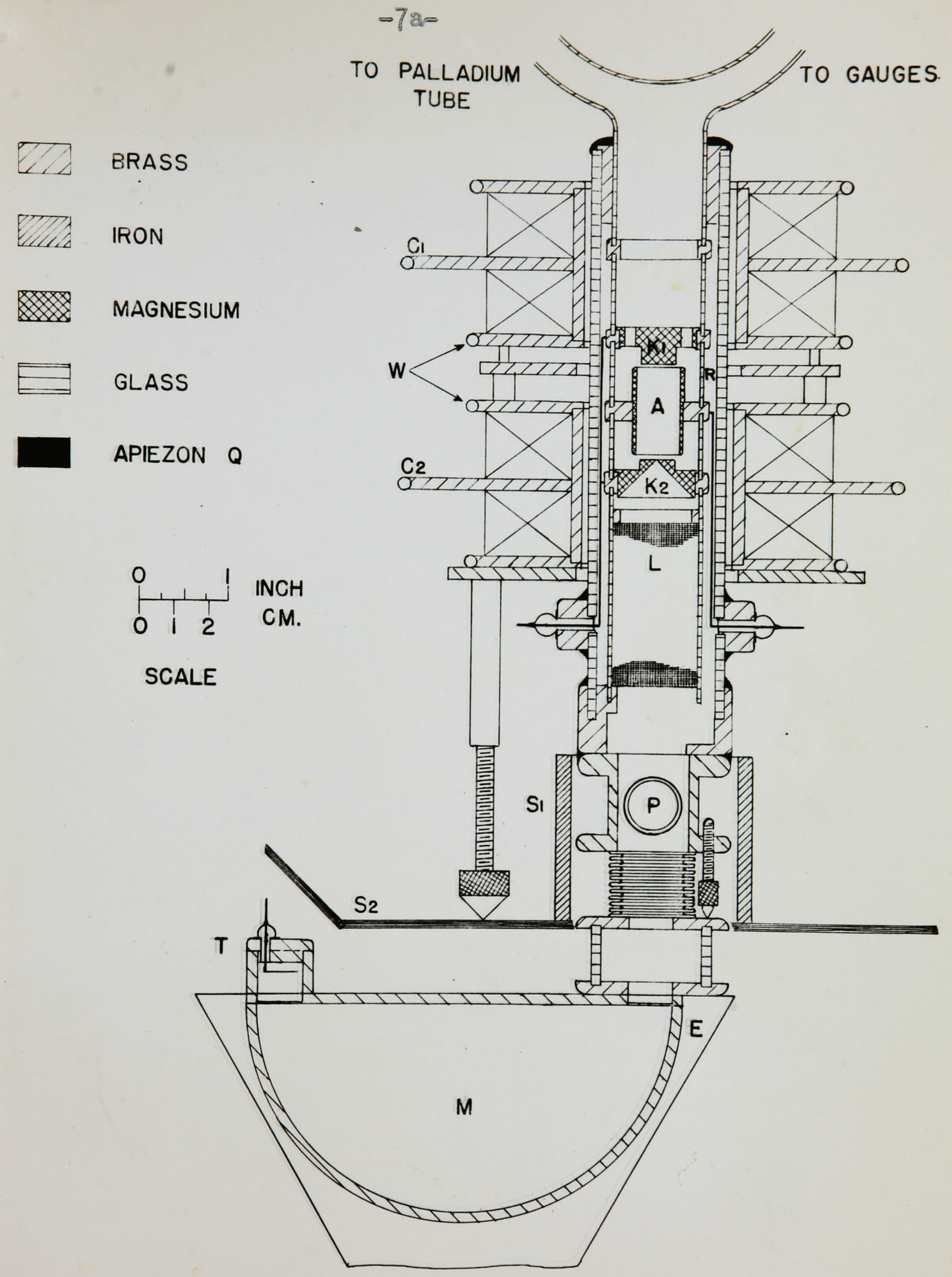

Hib. 2. Ion sourco and mass-gpectiograph. Gi, G, colls producing the magnetio field for the discharge; ". We Wer cooling; A, Anode; K, $\mathbb{K}_{2}$, cathodes;, low pressure region for the leads; L, sccelerating ${ }^{2}$ ens electrote, $P$, to pumps: Sq, S, magnetic shields; 焉, electromagret pole-plece; M, mass-spectrograph; r, collector. 


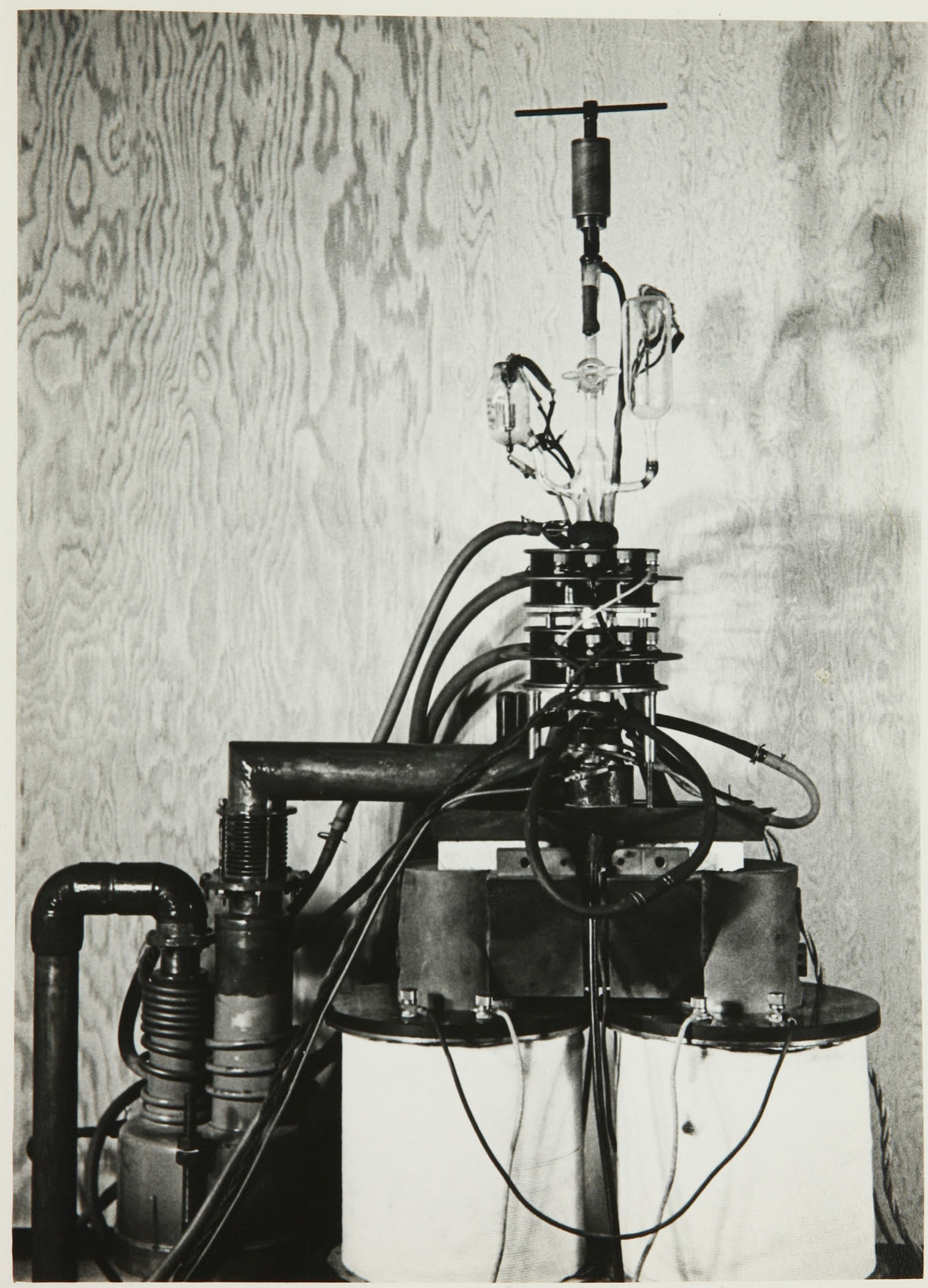

Fig. 2a. Photograph of the ion source and mass-spectrograph. 
An RCA 1946 thermocouple vacuum gauge with a Cenco Control Unit and a Distillation Products VG-2 ionization vacuum gauge were used. The calibration of the thermocouple gauge was assumed to be the same for pure hydrogen and for the mixture of about $90 \%$ of hydrogen, $10 \%$ of oxygen and $2 \%$ of water vapour which was used.

Fig. 2 shows the position of the gas inlet and of the vacuum gauges. The upper cathode $K_{1}$ had 8 holes around its circumference such that their aggregate pumping speed was much larger than that of the hole in $\mathrm{K}_{2}$. The gauge pressure was thus approximately equal to that in the discharge when the anode had an inner diameter of about 20 millimeters. For smaller anode diameters, the pumping speed at $\mathrm{K}_{1}$ was not sufficiently high and the gauge pressure was higher than the discharge pressure.

2. The Discharge Tube and the Beam-Forming Lens

The discharge tube was designed in view of the experimental work described below. The cathodes $\mathrm{K}_{1}$ and $\mathrm{K}_{2}$, and the anode 1 were made from $99.95 \%$ magnesium sticks supplied by Dominion Magnesium Limited, Toronto. The electrodes were supported on brass rings and glass spacers. The onds of the glass spacers were ground flat and the pumplng speed across these joints from the inner region to $R$ was very low. The whole was enclosed in a coaxial glass tube. $R$ was evacuated 
directly, as shown, and provided a low pressure region for the electrode leads. The brass rings supporting the electrodes were water cooled by means of loops of fine copper tubing replacing the wire leads shown in Fig. 1. This tubing was made by immersing standard 1/16" I.D., 1/8" 0.D. copper tubing in nitric acid until the wall thickness was reduced to $1 / 64^{n}$. This discharge tube was particularly convenient because: (a) dismantling or reassembling it involved only two Apiezon cement seals and thus required only a few minutes, (b) no trouble was experienced from spurious discharges at the leads, (c) the gauge pressure was approximately equal to the discharge pressure and, (d) the incoming gas was exposed only to glass and metal. The geometry of the cathodes was always the one shown. Anodes of various diameters and lengths were used. The electrodes, glass spacers and brass rings were cleaned by dipping them for a fraction of a second in concentrated hydrochloric acid, rinsing in tap water and distilled water, and drying with alcohol. To avoid contact with the hands, the cleaned parts were assembled with a glass rod.

The magnetic field required for the discharge was produced by a pair of specially designed water-cooled coils shown in Fig. 2. Each of the four sections was wound with 370 turns of No. $17 \frac{1}{2}$ B \& $S$ gauge HF Fornex wire. The magnetic induction along the axis was calculated to be 129 gauss per ampere within $\pm 1 \%$ over a distance of 3.3 centimeters on either 
side of the center. These coils could operate continuously at nagnetic fields of 1,000 gauss, and, for short periods, at fields up to 4,000 gauss.

The ions emerging from the lower cathode were formed into a beam by means of the electrostatic lens action of the lower conical surface of the cathode $K_{2}$ and the cylinder $L$. Copper wire cloth was used for $I$ so that the ion beam could be observed visually, but at the low pressures used, it could hardly be seen. A rounded brass ring at the top of $I$ reduced sparking.

Fig. 3 shows the power supplies and the associated circuits for the discharge tube and for the electrostatic lens. The meter $\mathrm{I}_{4}$ was, as explained below, either a vacuum tube voltmeter or an oscillograph. Magnetic voltage regulators were used for stabilizing the line voltage. The two cathodes were always at the same potential.

\section{The Mass-Spectrograph}

The mass-spectrograph used was of the Dempster type (6) with an ion path radius of 6.0 centimeters. The ion energy was held constant and the magnetic field was varied to focus the various types of ions on the slit of the collector $T$. The slits were about $1 / 2^{n}$ long and $1 / 64^{n}$ wide and the collector was a light molybdenum plate spot-welded to a Stupakoff Kovar seal as shown. Narrow slits were used so that the energy spread of the ion beam could be estimated. 


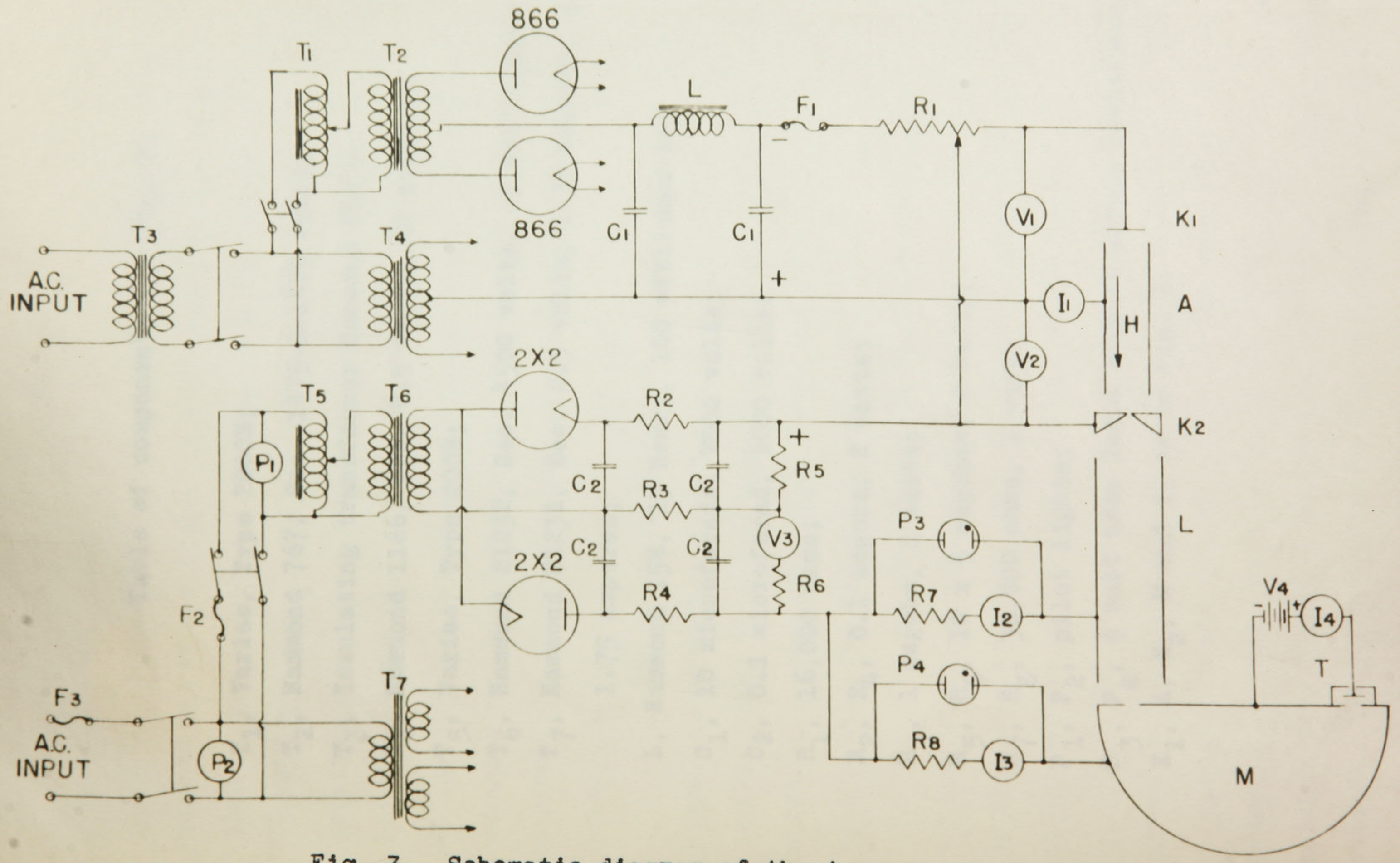
Fig. 3. Schematio diagram of the ion source, the mass-spectrograph
and the associated electrical circuits. 
Table of components for Fig. 2 .

$T_{1}$, Variac, Type 2000M;

$T_{2}$, Hammond 767, Sec. 1475-0-1475 volts;

$\mathrm{T}_{3}$, Insulating transformer Hammond 21230;

$T_{4}$, Hammond 1166, Sec. 2.5 volts, 10 amperes;

$\mathrm{T}_{5}$, Variac, Type 200B;

$T_{6}$, Hammond 21232 , Sec. 4500 volts, 17 milliamperes;

$\mathrm{T}_{7}$, Hammond 21231, Sec. 2.5 volts, 1.75 amperes, 2.5 volts, 1.75 amperes;

L, Hammond 158, 15 Henry, 100 milliamperes;

$c_{1}, 10$ microfarads, 2000 volts;

$c_{2}, 0.1$ microfarad, 6000 volts;

$R_{1}, 16,000$ ohms;

$\mathbf{R}_{2}, \mathbf{R}_{4}, 0.1$ megohm, 2 vatts;

$\mathrm{R}_{3}, 1$ megohm, 2 watts;

$R_{5}, R_{6}, 10 \times 5$ megohms, 2 watts;

$R_{7}, R_{8}, 30,000$ ohms, 1 watt;

$P_{1}, P_{2}$, pilot lights;

$P_{3}, P_{4}$, $\frac{1}{2}$ watt neon lamps without series resistances;

$\mathrm{K}_{1}, \Lambda, \mathrm{K}_{2}, \mathbb{M}$ and $\mathrm{T}$, as in $\mathrm{Fig} .2$. 
To reduce secondary electron emission from the collector, it was biased at +300 volts with respect to the body of the mass-spectrograph. Two iron blocks resting on the electromagnet pole pieces on either side of the collector provided a magnetic field which also served to reduce secondary emission. The variation of the collector current with the collector bias indicated that under these conditions secondary emission was negligible. The 300 volt bias actually had no appreciable effect on the percentage composition of the ion beam.

The curve of collector current against magnet current showed sharp maxima corresponding to the different types of ions in the beam. With the magnet current set for a maximum detector current, a change of about $1 \%$ in the former reduced the latter to one half its maximum value.

The collector current was measured with a vacuum tube voltmeter with a full scale sensitivity of $1.33 \times 10^{-7}$ ampere on the lowest range. The ion beam currents used for the mass analyses were of the order of 500 microamperes.

The percentage composition of the ion beam under a given set of conditions was always determined two or three times in succession and the mean percentages were used. With pure hydrogen, a mass analysis could be reproduced from one day to another within approximately the experimental error. For example, the points shown on Fig. 6 were taken on two different 
days, both sets of points covering the whole range of pressure. When a mixture of hydrogen, oxygen and water vapour was used, the reproducibility was not as good, but satisfactory, as can be seen from Figs. 10 and 11. The points for any given curve were always determined in random order to eliminate any possible time variation in the composition of the ion beam.

Direct observation of the mass spectrum on an oscillograph screen was made possible in the following manner. The mass spectrograph magnetic field was swept automatically at a frequency of about one cycle per second by opening and closing the circuit of the electromagnet with a switch operated by an electric motor and a cam. This provided a satisfactory approximation of a saw-tooth sweep of the magnetic field because of the inductance of the electromagnet. The voltage across a resistance in series with the electromagnet provided a horizontal sweep for a Dullont type 208 oscillograph arranged for D.C. amplification. The current from the collector $T$ was passed through a resistance of a few megohms and the voltage across this was fed to the Y-axis amplifier of the oscillograph. The oscillograph therefore displayed a graph of the detector current as a function of the magnetic field, 1.e., the mass spectrum. The accuracy of this method is limited by: (a) unavoidable "noise" in the discharge, producing rapid variations in the beam current; (b) nonlinearity of the oscillograph response; (c) frequency dependence of the oscillograph response, 
since the sweep is not strictly saw-tooth and the peaks are not all swept at the same speed. The effect of (a) is reduced by taking the average heights of the peaks for a few sweeps; (b) and (c) are relatively negligible. The agreement between the oscillograph and the vacuum tube voltmeter results was within the experimental error. This method has the great advantage of providing a continuous indication of the ion beam composition. It was extremely useful, especially for rapid qualitative observations. It permitted direct observation of time variations in the beam composition which would have been difficult to observe otherwise. 
II Results

\section{The Discharge}

The behaviour of the discharge is highly satisfactory at pressures above a few microns; ignition is practically instantaneous and the operation is very reliable. The magnetic field does not need to be uniform or accurately axial and can be supplied by a permanent magnet.

Cathodes of the shape shown in Fig. 2 concentrate positive ion bombardment of the cathodes and electron emission near the axis of the discharge. With flat cathodes, electrons emitted at their periphery reach the anode directly without oscillating and simply heat the anode without ionizing the gas.

Magnesium was used for the cathodes because of its low work function, its availability and its machinability. The green cathode light which is characteristic of magnesium (8) occurs only on that part of the cathode which projects in the anode cylinder.

It was observed that when the discharge is operated at potentials of the order of 1000 volts, the anode material sputtered on to the cathode. It is thus desirable to use the same material for both the anode and cathode if such high discharge voltages are expected to occur. 
The operation of the discharge is not changed appreciably if a ring is used as anode instead of a cylinder as in Fig. 2. A cylindrical anode was used here because it lends itself to ion source designs which are mechanically very satisfactory.

With hydrogen, a bluish-white plasma fills the anode cylinder. There is no definite dark-space near the cathodes when magnesium is used, but with brass cathodes the plasma shows a definite convex surface facing the cathodes. With cathodes as in Fig. 2, the plasma is more luminous near the axis of the discharge tube. At very low pressures, of the order of 0.01 micron, the luminous part of the discharge is a very fine line, about 1 millimeter in diameter, along the axis of the discharge tube. With magnesium, the green cathode light is then concentrated in a small spot at the center of the cathode.

Fig. 4 shows a typical set of curves of the discharge current as a function of the discharge voltage at various pressures. The discharge tube was similar to that of Fig. 2 but with an anode cylinder 60 millimeters in length and 20 millimeters in inner diameter. These curves are similar to those of a cold-cathode discharge between plane parallel electrodes in the absence of a magnetic field (33). The constant-voltage curves correspond to the "normal" discharge and the others to the "abnormal" discharge. The part of the characteristics which occurs at currents of a few milliamperes is not shown. For the constant voltage characteristics, the lgnition voltage is a few 


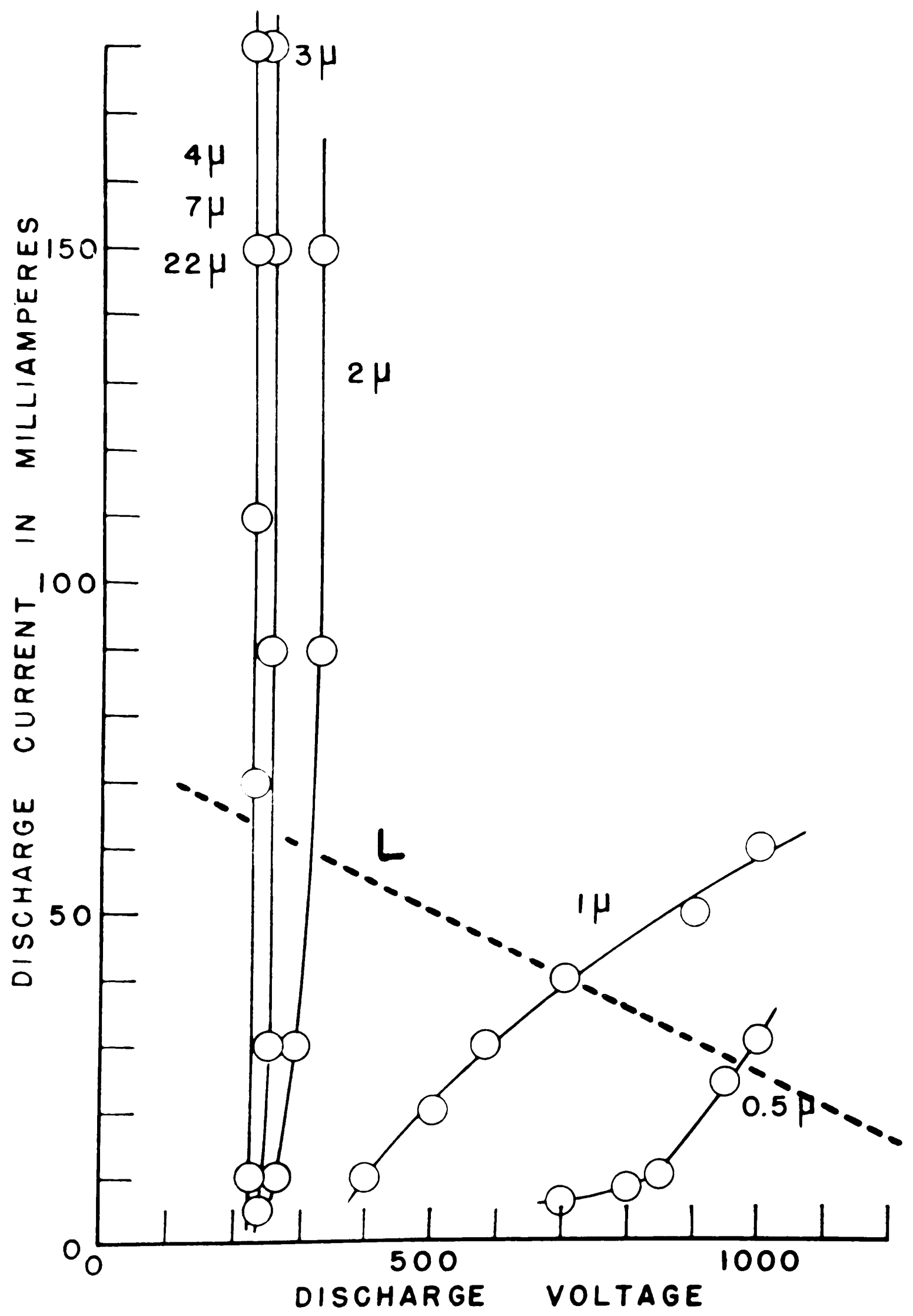

Fig. 4. Typical set of curves of the discharge current as a function of the discharge voltage, at various pressures, with pure hydrogen. Magnetic induction, 1300 gauss; anode length, 60 millimeters; anode diameter, 20 mililimeters. 


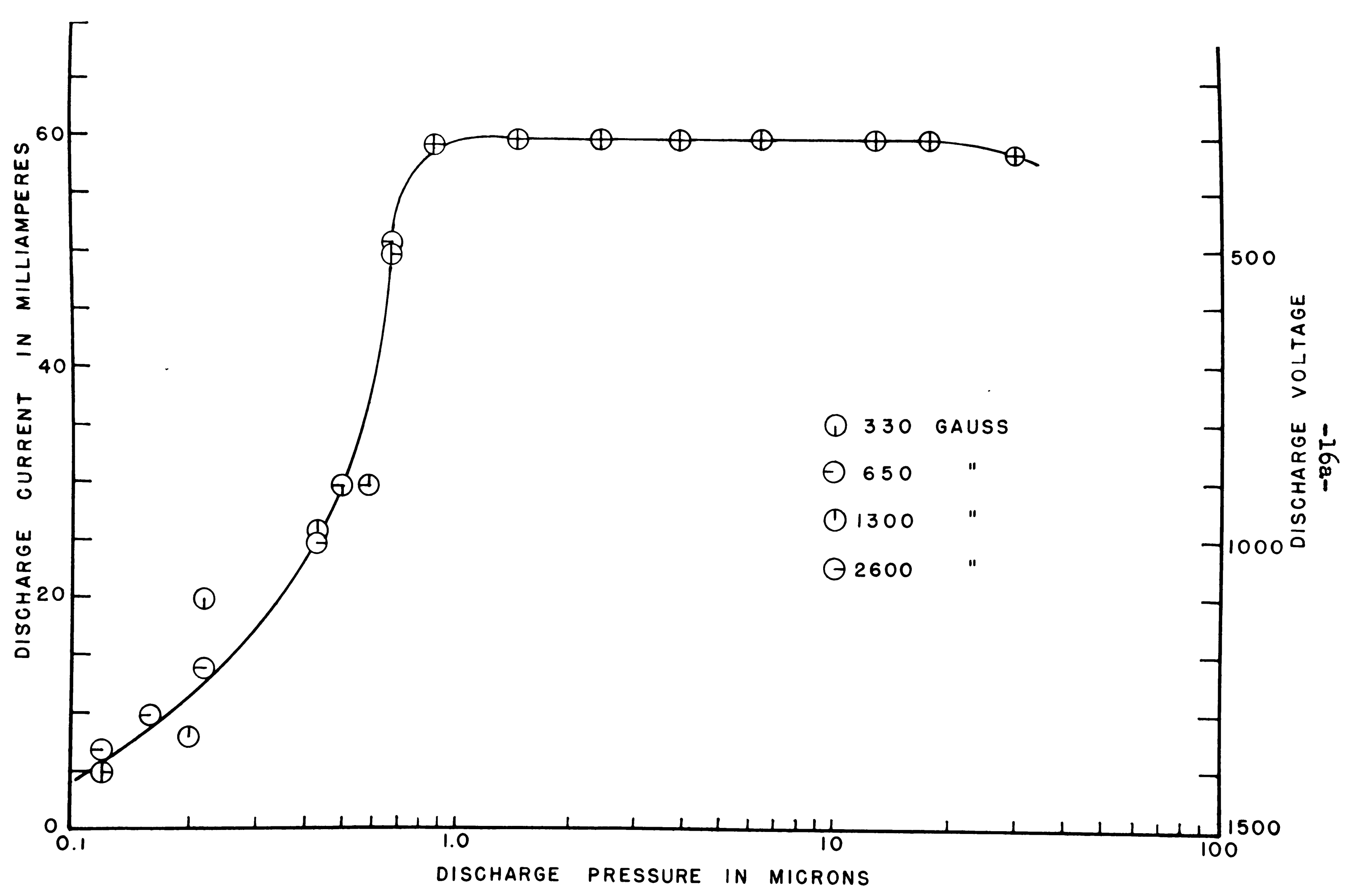

Fig. 5. Discharge voltage and current for various pressures and magnetic fields, with a mixture of $90 \%$ of hydrogen and $10 \%$ of oxygen collected over water. Power supply voltage, 1500
volts; series resistance, 20,000 ohms. Anode length, 26 millimeters; anode diameter, 20 millimeters 
shows the intersection of families of curves of the type of those of Fig. 4 with the resistance line L. A supply voltage of 1,500 volts and a series resistance of 20,000 ohms (including the internal resistance of the power supply) were used. The points corresponding to low pressures and high voltages must again be considered as qualitative.

Experience with many different discharge tubes of the same type and of the same order of size as the present ones has shown that the voltage-pressure characteristic, as in Fig. 5, is determined mainly by the cathode material, and not by the geometry of the electrodes or by their spacing.

\section{Proton Production}

Figs 6 and 7 show the percentage composition of the Ion beam as a function of the pressure, with pure hydrogen from a palladium diffusion tube, for anodes of two different sizes. The true discharge pressures for Fig. 6 are about the same as for Fig. 7; they are lower than the gauge pressures shown because of the small anode diameter used. The optimum proton content with pure hydrogen was never higher than about $10 \%$. The percentage of $\mathrm{H}_{3-1}^{+}$and $\mathrm{H}_{2-1}^{+}$lons, (see below), in the beam was of the order of $1 \%$.

With elsctrolytic hydrogen containing $0.3 \%$ of oxygen, the beam composition was extromely variable, the proton content varying, for example, from 10\% to $80 \%$ for apparently similar 


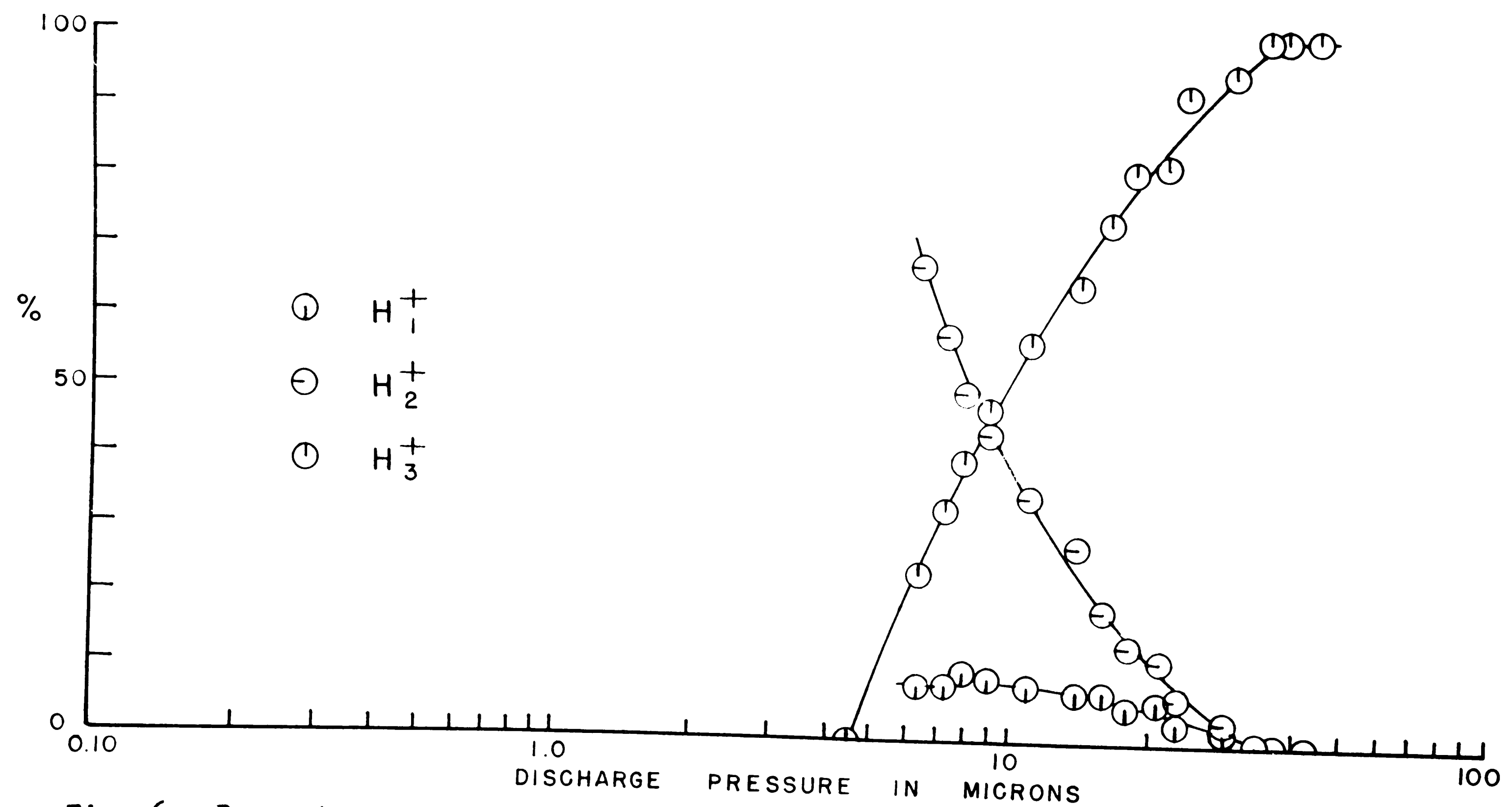

Fig. 6. Percentage composition of the ion beam as a function of the pressure, with pure Magnetic induction, 780 gauss. Anode length, 26 millimeters; anode diameter factor of about 3 . 
discharge conditions. The beam composition was especially variable at the beginning of a run when the discharge had not been operating for some time. No appreciable improvement was observed when the electrodes were water cooled. Similar inconsistencles have been observed by previous workers in this field (20). A set of curves of the percentage composition of the ion beam obtained under fairly steady conditions with electrolytic hydrogen was similar to those of Figs 8 and 9 with a maximum proton content of $12 \%$.

The very high proton percentages were highly encouraging, even though erratic. It appeared that the $0.3 \%$ of oxygen present in the electrolytic hydrogen reduced the recombination of atomic hydrogen at the walls of the discharge tube and thus provided a higher concentration of atomic hydrogen (see below).

Various poisons were added to the electrolytic hydrogen in the hope of obtaining a reliable high proton percentage in the ion beam. Air, water vapour and hydrogen chloride vapour had no appreciable effect. The hydrogen chloride vapour was added by bubbling the hydrogen in concentrated hydrochloric ac1d at 000 .

The addition of oxygen produced a definite improvement. For given discharge conditions, the proton percentage in the ion beam increased until the gas contained $10 \%$ of oxygen. Further addition of oxygen had little effect. Fig. 8 shows the ion beam composition for the same discharge tube as that of Fig. 7 


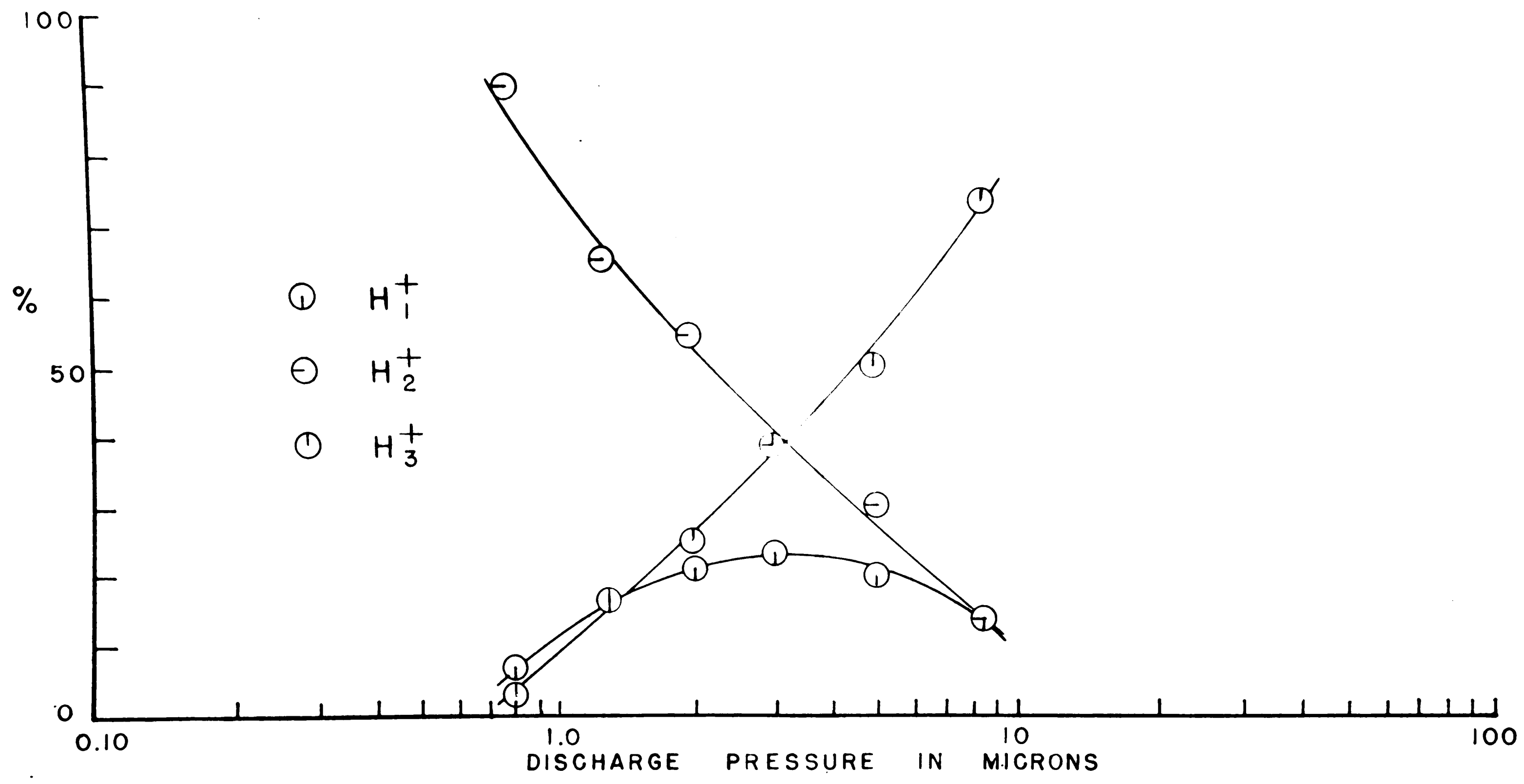

Fig. 8. Percentage composition of the ion beam as a function of the pressure, with a mixture of $90 \%$ of hydrogen and $10 \%$ of oxygen collected over water. Magnetic induction, 780 gauss. Anode length, 60 millimeters; anode diameter, 20 millimeters. 
and for the same operating conditions, but with a mixture of $90 \%$ of electrolytic tank hydrogen and $10 \%$ of tank oxygen collected over water at room temperature. Fig. 9 shows a similar set of curves for a shorter anode. The percentage of oxygen and other forelgn lons in the beam was only about $1 \%$. It is to be noted that the increase in the proton percentage was not accompanied by a corresponding decrease in the total ion current.

Fig. 10 shows the percentage composition of the ion beam for the same discharge tube and for the same gas mixture as for Fig. 9, at a pressure of 2 microns, for various discharge currents and magnetic fields.

Fig. 11 shows the variation in the lon beam composition at a discharge current of 30 milliamperes as the magnetic field 18 increased from 400 to 3,200 gauss.

When the ion beam is extracted from the edge of the cathode, its composition is about the same as when it is extracted from the center, as in Fig. 2 .

\section{Ionization Processes}

The probable ionization and dissociation processes in hydrogen are as follows $(1,7,14,16,25,27,34,35,36)$

$$
\begin{aligned}
\mathrm{H}_{2}+e & \rightarrow \mathrm{H}_{2}^{+}+2 e \\
& \rightarrow \mathrm{H}_{1}^{+}+\mathrm{H}_{1}+e \\
& \rightarrow \mathrm{H}_{1}^{+}+\mathrm{H}_{1}+2 e \\
\mathrm{H}_{2}^{+}+\mathrm{H}_{2} & \rightarrow \mathrm{H}_{1}^{+}+\mathrm{H}_{1}+\mathrm{H}_{2} \\
& \rightarrow \mathrm{H}_{3}^{+}+\mathrm{H}_{1}
\end{aligned}
$$




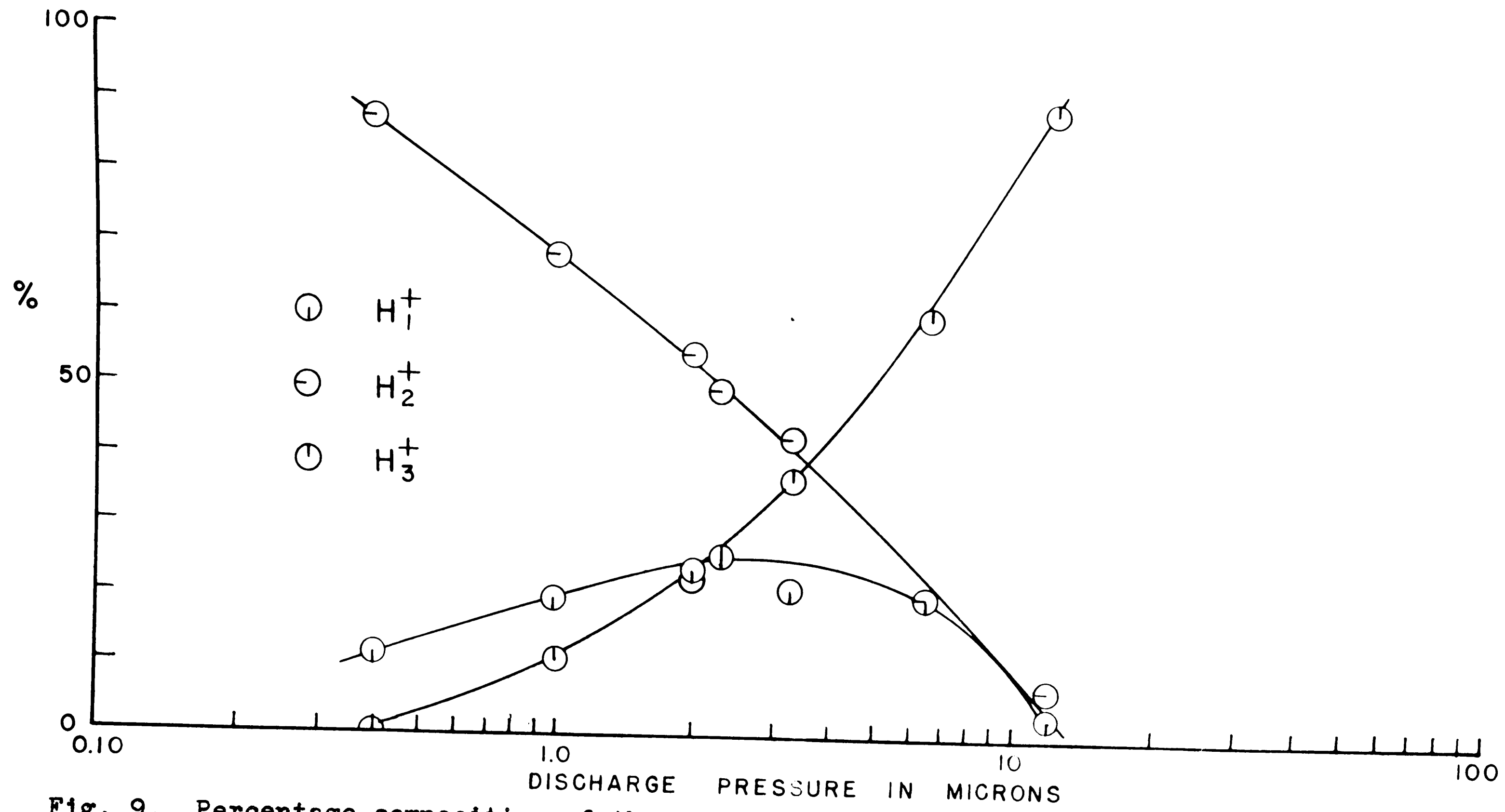
of $90 \%$ of hydrogen and $10 \%$ of oxygen collected over water Anode length, 26 millimeters; anode diameter, 20 mililmeters. 


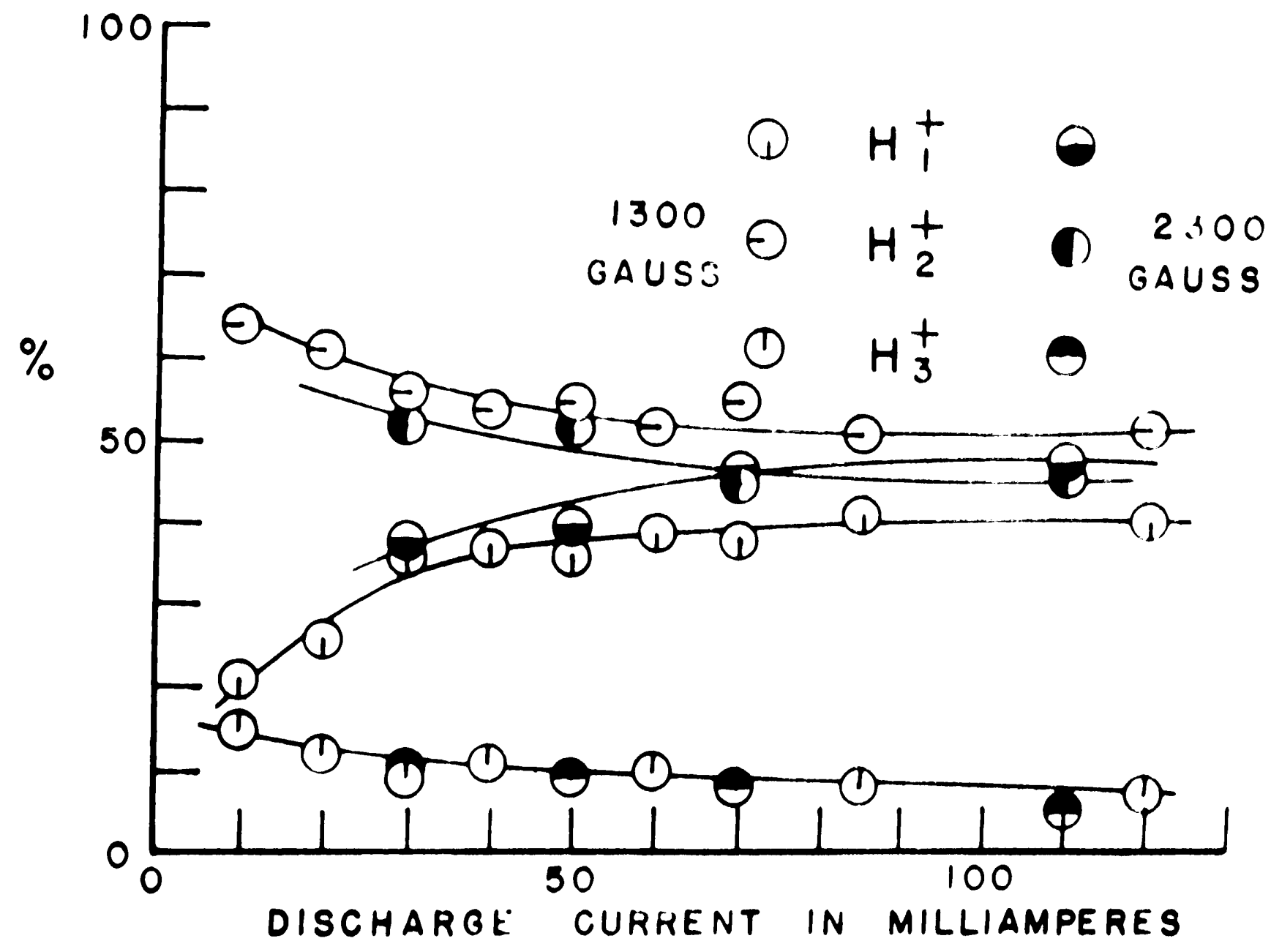

Fig. 10. Percentage composition of the ion beam as a function of the discharge current, with a mixture of $90 \%$ of hydrogen and 10\% of oxygen collected over water. Discharge pressure, 2 microns. Anode length, 26 millimeters; anode diameter, 20 millimeters. 


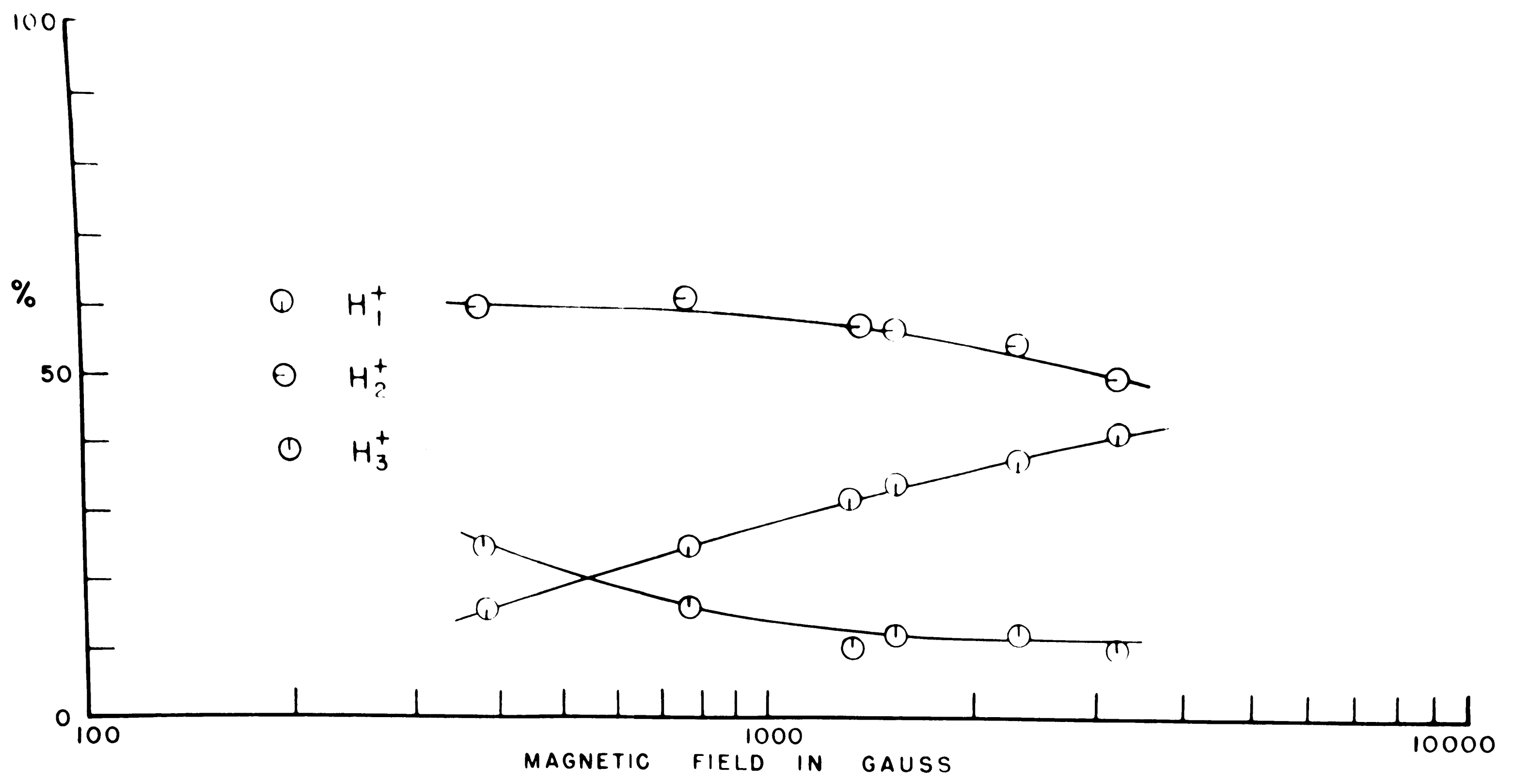

Fig. 11. Percentage composition of the ion beam as a function of the magnetic field at the discharge, with a mixture of $90 \%$ of hydrogen and $10 \%$ of oxygen collected over water. Discharge pressure, 2 microns; discharge current, 30 milliamperes. Anode length, 26 millimeters; anode
diameter, 20 mililmeters. 


$$
\begin{aligned}
& \mathrm{H}_{3}^{+}+\mathrm{H}_{2} \rightarrow \mathrm{H}_{1}^{+}+2 \mathrm{H}_{2} \\
& \mathrm{H}_{1}+e \rightarrow \mathrm{H}_{1}^{+}+2 e
\end{aligned}
$$

The ionization potentials for $(A)$ and $(C)$ are about 17 volts $(1,2,36)$. Molecular ions from (A) have energies of a fer electron volts, while atomic ions from (C) have thermal energies (27). The cross-section for (A) is a maximum for electrons of about 75 volts and is about 200 times that for (c) (27). Process (C) thus probably has little importance for a proton source. Reaction (B) has been investigated both experimentally $(7,16)$ and theoretically (25). Its cross-section is particularly high for 15 volt electrons, about 6 times the maximum cross-section for reaction (A). The reactions (D) and (F) are observed in mass-spectrographs when accelerated $\mathrm{H}_{2}^{+}$and $\mathrm{H}_{3}{ }^{+}$lons collide with neutral molecules before entering the magnetic field, giving rise to lons whose apparent mass is $1 / 2$ or $1 / 3$ of that of a proton, usually designated as $\mathrm{H}_{2-1}^{+}$or $\mathrm{H}_{3-1}^{+}(14,35)$. Glass and metallic surfaces catalyze the recombination of atomic hydrogen, but glass can be poisoned by mixing oxygen or water vapour with the hydrogen or by coating it with metaphosphoric acid. Tungsten surfaces can be poisoned with oxygen (43). The absence of dust and of organic matter is important, and the surfaces should preferably be $\operatorname{col}(9,37,43)$. Under optimum conditions, a hydrogen discharge tube operating at a pressure of 200 to 500 microns can contain 20 to $50 \%$ of atomic hydrogen $(37,43)$. 
In Figs 6 and 7 , the curves for $\mathrm{H}_{2}^{+}$and $\mathrm{H}_{3}^{+}$show the high probability of reaction $(\boldsymbol{E})$ : as the pressure is increased, the percentage of $\mathrm{H}_{3}^{+}$lons decreases while that of $\mathrm{H}_{3}^{+}$ions increases until the beam is composed almost exclusively of $\mathrm{H}_{3}^{+}$ The $\mathrm{H}_{3}^{+}$ions appear to be formed mainly through reaction $(E)$. The competing reaction (D) cannot thus be the main source of atomic 10ns, since the $\mathrm{H}_{1}^{+}$and $\mathrm{H}_{3}^{+}$curves are entirely different in shape. Now the $8 \%$ of atomic ions which is found at the lower pressures when the percentage of $\mathrm{H}_{3}^{+}$is negligible cannot be attributed to $(F)$. Also, from the fact that the percentage of $\mathrm{H}_{3}^{+}$rises to 100 at the higher pressures, it must be inferred that reaction (F) is quite rare in the present discharge. Then the atomic ions must originate mainly from $(G)$. The atomic hydrogen required can be produced either through (B) or through (I). The latter reaction obviously contributes very little to the formation of atomic ions here, since the percentage of $\mathrm{H}_{1}^{+}$ decreases as that of $\mathrm{H}_{3}^{+}$increases.

By a process of elimination, one is thus led to believe that, in the present source, the atomic lons are formed mainly through (B) and (G):

$$
\begin{aligned}
& \mathrm{H}_{2}+e \rightarrow \mathrm{H}_{1}+\mathrm{H}_{1}+e \\
& \mathrm{H}_{1}+e \rightarrow \mathrm{H}_{1}^{+}+2 e
\end{aligned}
$$

The importance of these two reactions is confirmed by the fact that much higher percentages of atomic lons are found when the 
walls of the discharge tube are polsoned to reduce the rate of recombination of atomic hydrogen and thus increase its concentration in the gas.

It is now possible to explain the observed gradual increase in the proton percentage with increasing pressure, when pure hydrogen is used.

For a given electron density and energy distribution, the probability that an lonizing electron will produce an atomic ion is proportional to the relative concentration of atomic hydrogen in the gas. Setting $\left(\mathrm{H}_{1}^{+}\right)$as the number of atomic ions impinging on the cathodes per unit time, and $\left[\mathrm{H}_{1}\right]$ and $\left[\mathrm{H}_{2}\right]$ as the numbers of $\mathrm{H}_{1}$ atoms and $\mathrm{H}_{2}$ molecules in the discharge tube,

$$
\left(\mathrm{H}_{1}^{+}\right)=\mathrm{K}_{1} \frac{\left[\mathrm{H}_{1}\right]}{\left[\mathrm{H}_{1}\right]+\left[\mathrm{H}_{2}\right]}
$$

where $K_{1}$ depends on the electron density and energy distribution, and on the cross-section for process $(G)$.

Similarly, we have

$$
\left(\mathrm{H}_{2}^{+}\right)=\mathrm{K}_{2} \frac{\left[\mathrm{H}_{2}\right]}{\left[\overline{\mathrm{H}}_{1}\right]+\left[\mathrm{H}_{2}\right]}-\left(\mathrm{H}_{3}^{+}\right)
$$

where $\left(\mathrm{H}_{2}^{+}\right)$and $\left(\mathrm{H}_{3}^{+}\right)$are the numbers of $\mathrm{H}_{2}^{+}$and $\mathrm{H}_{3}^{+}$ions impinging on the cathodes per unit time, and $K_{2}$ is similar to $K_{1}$.

In a glow-discharge, under steady conditions, the positive ions which are produced, either directly or through an avalanche effect, by an electron emitted at the cathode, are just sufficient to extract one other electron from the cathode. If a number of different types of positive ions are produced, 
and if their relative numbers change with the pressure, the ratio of electron to positive lon current at the cathodes can also change. However, this is probably not the case for the constant-voltage discharge, and our first assumption $\$ 111$ be that the ratio of the positive ion current to the total current at the cathodes is a constant $\mathrm{K}$ independent of the pressure. Very little is known about the emission of electrons from metals submitted to positive ion bombardment and this is the only possible assumption.

sdding now equations (H) and (I) we have

$$
\begin{aligned}
\left(\mathrm{H}_{1}^{+}\right)+\left(\mathrm{H}_{2}^{+}\right)+\left(\mathrm{H}_{3}^{+}\right) & =\frac{\mathrm{K}_{1}\left[\mathrm{H}_{1}\right]+\mathrm{K}_{2}\left[\mathrm{H}_{2}\right]}{\left[\mathrm{H}_{1}\right]+\left[\mathrm{H}_{2}\right]} \\
& =\mathrm{KI}
\end{aligned}
$$

Where I is the discharge current. The right-hand side of $(J)$ Is thus independent of the pressure, i.e. of $\left[\mathrm{H}_{1}\right]+\left[\mathrm{H}_{2}\right]$, and

$$
\mathrm{K}_{1}=\mathrm{K}_{2}=\mathrm{KI} \text {. }
$$

From equations (H) and (I) we have now

$$
\begin{aligned}
\frac{\left(\mathrm{H}_{1}^{+}\right)}{\left(\mathrm{H}_{1}^{+}\right)+\left(\mathrm{H}_{2}^{+}\right)+\left(\mathrm{H}_{3}^{+}\right)} & =\frac{\left[\mathrm{H}_{1}\right]}{\left[\mathrm{H}_{1}\right]+\left[\mathrm{H}_{2}\right]} \\
& =\frac{p_{1}}{p}
\end{aligned}
$$

where $p$ is the pressure in the discharge tube and $p_{1}$ is the partial pressure of atomic hydrogen.

Now if atomic hydrogen is produced at a rate $\left(\mathrm{H}_{1}\right)$ atoms per unit time, the steady state number of atoms $\left[\mathrm{H}_{1}\right]$ in 
the discharge tube $\mathbf{w 1 1}$ be given by

$$
\frac{d}{d t}\left[H_{1}\right]=\left(H_{1}\right)-B\left[H_{1}\right]-A\left[H_{1}\right]^{2}=0
$$

where $B\left[\mathrm{H}_{1}\right]$ and $\Delta\left[\mathrm{H}_{1}\right]^{2}$ are the rates of recombination, in atoms per unit time, on the walls of the discharge tube and in the gas, respectively. The rate at which atomic hydrogen is removed from the gas by lonization is negligible. The coefficients $A$ and $B$ depend on the nature of the gas. B also depends on the nature of the surfaces exposed to the gas, and probably varies with the pressure.

Our first assumption was that the number of ion pairs produced in the discharge per electron emitted at the cathodes was independent of the pressure; our second assumption will be that the number of hydrogen atoms produced per electron emitted at the cathodes is also independent of the pressure. Both of these assumptions are justifiable as follows. The trajectories described by the electrons between collisions, under the influence of the axial magnetic field and of the radial electric field due to their own negative space charge, are similar (neglecting axial motion) to those of electrons in a magnetron operated beyond cut-off. There is then no radial drift and it is only in a collision that an electron can alter its trajectory and approach the anode. An electron of given position and velocity therefore undergoes, on the average, a number of collisions which Is independent of the pressure. 
For a constant discharge current, the rate of production of atomic hydrogen, $\left(H_{1}\right)$, is thus independent of the pressure. We may assume, for the moment, that $B$ is also independent of the pressure, like $A$. Then $\left[\mathrm{H}_{1}\right]$, and thus $\mathrm{p}_{1}$, are independent of the pressure, by equation $(0)$.

Under the above two assumptions, and for a constant discharge current, we have from equation (N) that the percentage of atomic ions impinging on the cathodes and in the canal $r$ ay should vary inversely with the pressure. The same relation holds for lons extracted through an opening in the anode.

This is roughly correct, as can be seen from Figs 6 and 7. Lt the lower pressures, however, the percentage of atomic lons in the beam is quite constant, while at the higher pressures it rapidly becomes negligible. The shape of the $\mathrm{H}_{1}^{+}$curve at the low pressure end can be accounted for by the outgassing of the discharge tube walls, a resultant increase in $B$ and a decrease in $\left[\mathrm{H}_{1}\right]$. It seems difficult to explain the absence of the atomic ions at the bigher pressures.

The results of other workers in this field hardly agree with each other and with the present results. This can be attributed to differences in the energy distribution of the ionizing electrons, and in the discharge tube surfaces.

H. D. Smyth's results on the primary and secondary products of ionization in hydrogen (35), when plotted as in Figs 6 and 7 give for the ion $\mathrm{H}_{2}^{+}$a curve which is entirely similar to 
the present ones, but his curve for $\mathrm{H}_{3}^{+}$shows no discontinuity at the low pressures, and his maximum percentage of $\mathrm{H}_{3}^{+}$is only about 80. He observed an increase in the percentage of atomic lons with pressure and attributed their formation to reaction (D). L. P. Smith and G. W. Scott $(32,34)$ have reported a proton source for which the atomic ion percentage decreased sharply with pressure. Upon plotting their results, it is found that their atomic ion percentage varied approximately inversely with the pressure. The above discussion, however, does not apply to their source, for the electron current and path length were fixed, so that $\left(\mathrm{H}_{1}\right)$ was certainly not independent of pressure. These authors explain the formation of atomic hydrogen in their source by reactions $(B)$ and $(G)$ at 10 pressures and also by (C) and by $(A),(E)$ and $(G)$. They do not give data on the $\mathrm{H}_{2}^{+}$and $\mathrm{H}_{3}^{+}$ions.

0. Luhr (24) has observed that hydrogen ions aged to $10^{5}$ collisions in hydrogen at a pressure of 300 microns contain $10 \%$ of $\mathrm{H}_{1}^{+}, 10 \%$ of $\mathrm{H}_{2}^{+}$and $80 \%$ of $\mathrm{H}_{3}^{+}$. This is not in agreement with the present results nor with $H . D$. Smyth's curves.

The marked increase in the proton percentage which occurs upon the addition of oxygen and of water vapour to the hydrogen (Figs 8 and 9 ) is presumably due to a decrease in $B(43)$, causing an increase in $\left[\mathrm{H}_{1}\right]$ and in $\mathrm{p}_{1} / \mathrm{p}$, according to equations $(0)$ and (N). At the lower pressures, outgassing probably occurs and the surfaces favour the recombination of atomic hydrogen as 
If the oxygen and the water vapour were not present.

The curves of Figs 10 and 11 showing the composition of the ion beam as a function of the discharge current and of the magnetic field can be explained qualitatively according to the above discussion. The rate of production of atomic hydrogen, $\left(\mathrm{H}_{1}\right)$, should increase with the density of the slow electrons available for dissociation in the discharge tube, and thus with the discharge current. When the magnetic field is increased at constant discharge current, the rate of drift of the electrons towards the anode is reduced and the density of slow electrons increases. Then, increasing elther the discharge current or the magnetic field should (a) increase the percentage of atomic ions, according to equations $(\mathrm{O})$ and $(\mathrm{N})$; (b) reduce the percentages of both the $\mathrm{H}_{2}^{+}$and $\mathrm{H}_{3}^{+}$ions, if these are formed according to equations (A) and $(E) ;(C)$ reduce the ratio of the percentage of $\mathrm{H}_{3}^{+}$to the percentage of $\mathrm{H}_{2}^{+}$if the $\mathrm{H}_{3}^{+}$lons are formed according to equation (E).

\section{Ion Extraction}

A positive ion beam can be extracted from a gas discharge either in the form of a canal-ray through a hole in the cathode or directly from the discharge plasma. Figs $12(a)$ and 12(b) show schematically these two types of extraction with the present type of discharge. Fig. $12(c)$ is a proposed modification of Fig. 12(b) for the cyclotron. 


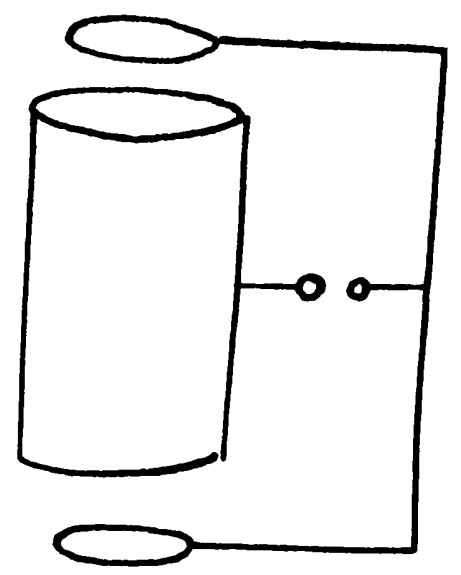

Fig. $12 a$

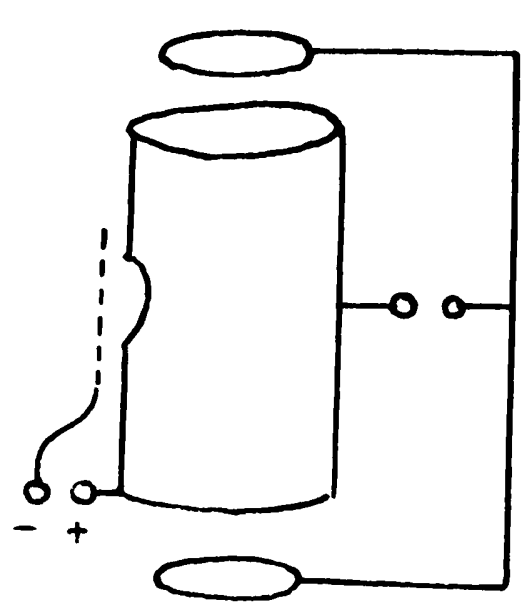

Fig. $12 b$

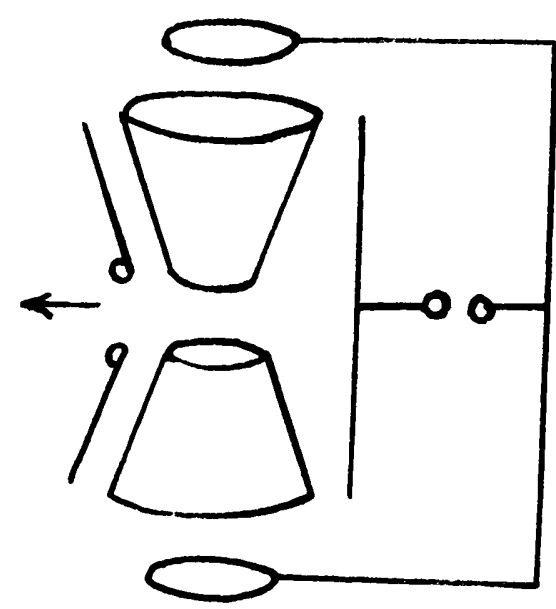

Fig. $12 \mathrm{c}$

The first two types were investigated very briefly. Unfortunately, time did not allow a more thorough investigation of the ion extraction. No attempt was made to obtain large ion beam currents. The results obtained, however, will indicate orders of magnitude, if not optimum conditions.

For the former case, discharge tubes similar to that shown in Fig. 2 and varying only as to the dimensions of the anode cylinder, were used. The hole in $\mathrm{K}_{2}$ had a diameter of 3 millimeters and its area was $3 \%$ of that part of the cathodes which projects in the anode cylinder. Under these conditions, the ratio of the total ion beam current (including secondary electrons) to the discharge current varied from $2 \%$ to $1 \%$ as the discharge current was increased from 10 to 100 milliamperes. The dimensions of the anode had but little effect on this ratio. The pressure 
also had little effect, as long as the discharge was operated in the constant-voltage region.

A small hole was used in $K_{2} 80$ as to maintain a low pressure in the mass-spectrograph. A somewhat larger hole would presumably have given a higher ratio of lon beam current to discharge current.

The extraction was much more efficient at low pressures and high discharge voltages. In one case, for instance, the ratio of the ion beam current to the discharge current was $1.3 \%$ when the discharge was operated at 300 volts, while it was $16 \%$ at 1000 volts. Unfortunately, this high efficiency of extraction cannot be utilized, as it is accompanied by a relatively low efficiency of proton production.

An ion beam can also be extracted from the discharge plasma through a side hole in the anode cylinder by means of a grid maintained at a negative potential with respect to the anode, as in Fig. 12b. In the one source of this type which was built, the anode cylinder was 25 millimeters $10 \mathrm{ng}$ and 13 millimeters in diameter, and was drilled with a side hole 6 millimeters in diameter. The grid was at a distance of a few millimeters from the hole and its transparency was roughly 25 or $50 \%$. The ion beam current increased as the grid was made more negative with respect to the anode, until the extracting potential was about 500 volts. A further increase in the extracting potential had little effect on the ion beam current. 
Under these conditions, the ratio of the ion beam current (including the current to the grid and secondary electrons to the discharge current was about 10\%. The grid intercepted most of the ions, but with a proper design, the current to the extracting electrode could probably be less than one half of the total ion current. The effective ratio of the ion beam current (including secondary electrons) to the total discharge current can thus be taken as 5\% for the above discharge tube.

The ratio of the number of protons to the number of unionized particles emitted by the source can be calculated approximately as follows. Let

$N_{\mathfrak{u}}=$ Number of unionized particles emitted by the source per second;

$N_{1}=$ Number of ionized particles emitted per eecond;

$\mathrm{N}_{\mathrm{p}}=$ Number of protons emitted per second;

$i_{m}=$ Measured ion beam current, in milliamperes;

$i=$ True ion beam current in milliamperes;

$d=$ Diameter of the orifice through which the ion

beam is extracted;

$p=$ Pressure in the discharge tube, in microns;

$\mu$ = Average molecular weight of the gas used.

Then

$$
\mathbb{N}_{1}=6.3 \times 10151
$$

Assuming that the pressure in the discharge tube is much higher than that in the mass speotrograph (or in the ion accelerator), 
and that the gas temperature in $500{ }^{\circ} \mathrm{K}(4)$,

$$
\mathrm{N}_{\mathrm{u}}=1.26 \times 10^{16} \frac{\mathrm{d}^{2} \mathrm{p}}{\sqrt{\mathrm{M}}}
$$

The gas mixture, composed of about $90 \%$ of hydrogen, $10 \%$ of oxygen and $2 \%$ of water vapour, which was used, had an average molecular weight of about 4, assuming that 50\% of the hydrogen in the discharge tube was in the atomic state. We thus have

$$
\frac{N_{1}}{N_{u}}=\frac{1}{d^{2} p}
$$

In the present case, the measured ion beam current $1_{m}$ included the secondary electron current; a rough correction for this can be made by writing $1=1 \mathrm{~m} / 1.5$. Then, since about $50 \%$ of the ions formed were protons, under optimum conditions,

$$
\frac{N_{p}}{N_{u}}=\frac{1_{m}}{3 d^{2}}
$$

For the case of end-wise extraction through one of the cathodes, we had, in one case, $1_{m}=1$ milliampere, $d=2$ millimeters and $p=2$ microns, and

$$
\frac{N_{p}}{N_{u}}=4.2 \%
$$

This is not a maximum value; higher values of $\mathrm{N}_{\mathrm{p}} / \mathrm{N}_{\mathrm{u}}$ could be obtained by using a higher discharge current. A change in the size of the orifice in the cathode at constant discharge current would not produce a large change in this ratio, since $\mathbb{N}_{1}$ and $\mathbb{N}_{p}$ are probably proportional to the area of the orifice, like $\mathbb{N}_{u}$, 
to a first approximation.

With side-wise extraction through a hole in the anode cylinder, the discharge currents used were 10w, about 10 milliamperes and the resulting value of $\mathrm{N}_{p} / \mathrm{N}_{u}$ was about one tenth of the above value. The ion beam current per unit area of the extraction hole and per unit discharge current was about 2.5 times lower for side-wise extraction than for end-wise extraction.

The ratio of the proton current, in microamperes, in the ion beam, to the wattage $W_{d}$ dissipated in the discharge for end-wise extraction, with 250 volts and 100 milliamperes at the discharge, and 1 milliampere in the ion beam, was 13 microamperes per watt. Again, this is not the maximum value; higher values could be obtained by using a larger extraction hole.

For side-wise extraction, with 250 volts and 10 milliamperes at the discharge, and 0.5 milliampere in the ion beam, the above ratio was 67 microamperes per watt. This is probably about the optimum value for side-rise extraction. The dissipation of the heat developed in the source for either type of extraction presents no serious problem.

The table below shows how the above ratios compare with those for a few other types of source.

The energy of the extracted ions, for end-wise extraction, is given approximately by the discharge voltage. The energy spread was low, as could be judged by the sharpness of the maxima of the mass spectrum, less than $1 \%$ of the mean energy, 
1.e., less than about 2 volts. When the discharge was operated at high voltages, the energy spread was very much larger and increased with the discharge voltage.

With side-rise extraction, the energy of the extracted ions is presumably thermal.

The intensity of the ion beam current can be varied, for both types of extraction, by varying the discharge current with a rheostat in series with the discharge.

An electron beam can be extracted from the discharge by applying a positive potential on the cylinder L (Fig. 3 ). The electrons give a much more luminous beam than the positive ions because of their higher efficiency for excitation and Ionization (4). A fine sharp beam was obtained with an accelerating potential of only 20 volts on $L$, indicating that the energy of the electrons as they emerged from $\mathrm{K}_{2}$ was very low. M. von Ádenne has designed a source which can supply either a positive Ion or an electron beam, for use with a Van de Graff accelerator (40).

The ion source shown in Fig. 2 was designed purely for the purpose of investigating its discharge characteristics and its mass spectrum. It would not be very convenient as an ion source for an accelerator. In designing such a source, a choice -11l have to be made between end-wise and side-rise extraction of the ion beam. The latter type of extraction has the distinot advantage that it permits the use of the high magnetic field of a C type permanent magnet. A mass analysis of the ion beam could 
probably be made in the field of a second $C$ type magnet near the discharge tube where the ion beam has an energy of only a fow hundred volts. The magnetic fields of the two magnets would be parallel and would not interfere with each other. M. von Ardeene has described a mass-monochromator which could be used with either type of extraction (39).

With end-wise extraction, it seems that the magnetic field for the discharge must be provided by one or two co11s, as in Fig. 2. A tubular permanent magnet surrounding the discharge tube can also be used (42), but then the magnetic induction is only a $f e$ hundred gauss and the optimum proton percentage is probably about $20 \%$. 
Conclusions

The ion source described above possesses to a satisfactory degree the desirable characteristics enumerated in the Introduction. It will require, however, a further investigation of the ion extraction. It is quite possible that further work on the polsoning of surfaces would lead to proton percentages considerably higher than the 50\% reported above.

The table shown below will serve to compare the present source with the various other types. 
Approximate Characteristics of Various Types of Positive Ion Source

\begin{tabular}{|c|c|c|c|c|c|c|c|}
\hline \multirow[t]{2}{*}{ Type } & Year & Filament & $\begin{array}{l}\text { Energy } \\
\text { Spread }\end{array}$ & 1 & $\frac{1 p}{1}$ & ${ }^{1} p$ & $\frac{N_{p}}{N_{u}}$ \\
\hline & & & volts & $\begin{array}{l}\text { milli- } \\
\text { amperes }\end{array}$ & $\%$ & $\begin{array}{l}\text { m1cro- } \\
\text { amperes/ } \\
\text { watt }\end{array}$ & $\%$ \\
\hline $\begin{array}{l}\text { Low-Pressure Glow- } \\
\text { Discharge (Penning) } \\
(30)\end{array}$ & 1937 & No & 25,000 & 0.45 & 10w & low & low \\
\hline $\begin{array}{l}\text { Palladium Tube } \\
(12,13)\end{array}$ & 1938 & & thermal & 0.2 & 8 & $?$ & $?$ \\
\hline Cyclotron (21) & 1939 & Yes & 50 & $\sim 100$ & $\sim 10$ & $\sim 5.6$ & $\sim 4.2$ \\
\hline Electron Beam (34) & 1939 & Yes & 500 & 1 & 60 & 3 & 6 \\
\hline $\begin{array}{l}\text { Low-Pressure Arc } \\
\text { (Finkelstein) (10) }\end{array}$ & 1940 & Yes & 50 & 150 & $?$ & $?$ & $?$ \\
\hline Pyrex Cap1llary ( $2 \varnothing$ & 1941 & Yes & 30 & 1.5 & 60 & 6.7 & 3.6 \\
\hline Canal-Ray Tube (5) & 1942 & No & 25,000 & 1.5 & 45 & 1 & 0.2 \\
\hline $\begin{array}{l}\text { Low-Pressure Arc } \\
\left(\begin{array}{l}\text { von Ardenne }) \\
(39,40)\end{array}\right.\end{array}$ & 1943 & Yes & 100 & 0.1 & 50 & 5 & 0.4 \\
\hline $\begin{array}{l}\text { H1gh-Frequency } \\
\text { D1scharge }\left(38^{8}\right)\end{array}$ & 1946 & No & 20,000 & 0.25 & $?$ & $?$ & $?$ \\
\hline $\begin{array}{l}\text { Low-Pressure } \\
\text { Glow-Discharge } \\
\text { (Present work })\end{array}$ & 1946 & No & $<2$ & 1 & 50 & 67 & 4.2 \\
\hline
\end{tabular}




\section{Appendix}

Another type of low-pressure glow-discharge, the "inverted magnetron", was investigated briefly and seems worthy of mention.

The "inverted magnetron" discharge occurs between a pair of coaxial cylinders, the outside one being the cathode and the inside one the anode, in the presence of an axial magnetic field. Ilectrons emitted at the cathode describe long cycloidal paths in planes perpendicular to the magnetic field before reaching the anode. Fnd plates connected to the cathode prevent the electrons from escaping out of the discharge. A Penningtype discharge can take place between the end plates and the Inner cylinder, (29), but, when the length of the cathode is about twice its diameter, metal from the cylinder wall is sputtered on the end plates, showing that the positive ion bombardment and the electron emission occur mostly at the cylinder walls. In one case, the cathode was 1 inch long and $1 / 2$ inch in diameter, the anode was $3 / 16$ inch in diameter, and the gap between the and-plates and the anode was $1 / 16$ inch. The characteristics of ihis discharge are very similar to those of the discharge disisssed above. F. M. Penning has made a study of the "inverted lagnetron" with a view to using it as a high voltage rectifier (28). 
Acknowledgements

The writer wishes to express his thanks to Dr. J. S. Foster and to Dr. B. W. Sargent for suggesting the problem and for making the necessary arrangements so that it could be inrestigated at the Montreal Laboratory of the National Research Council in the summer of 1945, to Dr. A. N. Shaw for his constant encouragement, and to Mr. A. G. Ward for his invaluable advice in the first few months of this work. Thanks are also due to the members of the "Departement de Physique" of the "Universite Laval", where the major part of the research was done, and especially to their director, Dr. F. Rasetti, for their encouragement. Finally, the writer wishes to express his indebtedness to the National Research Council for the award of a Grant for Research which greatly facilitated the progress of the work. 


\section{Bibliography}

(1) Bleakney, W., Phys. Rev., 35, 1180 (1930).

(a) Brode, RB., Rev. Mod. Phys., 5, 257 (1933).

(3) Burcham, W.E., Unpublished report MP-176, "The Development of a Source of Fast Neutrons of Variable Bnergy", National Research Council of Canada, 1945.

(4) Cobine, J. D., "Gaseous Conductors".

(5) Craggs, J. D., Proc. Phys, Soc., 54, 245 (1942).

(6) Dempster, A. J., Phys. Rev., 11, 316 (1918).

(7) Dorsch, K. E. and Kallmann, H., Zeits. f. Phys., 53, 80 (1940)

(8) Druyresteyn, M. J. and Penning, F. M., Rev. Mod. Phys., 12, 87 (1940).

(9) Farkas, A. and Melville, H. W., "Experimental Methods in Gas Reactions".

(10) Finkelstein, A. T., R. S. I., 11, 94 (1940).

(11) Fowler, R. D. and Gibson, G. E., Phys. Rev., 46, 1075 (1934).

(12) Franzini, T., Nuovo Cimento, 15, 88 (1938).

(13) Franzini, T., Att1. Accad. Lincei, 27,292 (1938).

(14) Friedlander, E. and others, Zeits. f. Phys., 76, 60 (1938).

'15) He11, H., Zeits. f. Phys., 120, 212 (1943).

16) Hughes, A. L. and Skellet, A. M., Phys. Rev., 30, 11 (1927).

17) Hulubei, H., Compt. Rend., 199, 199 (1934).

18) Jossem, E. I., R. S. I., II, 164 (1940).

19) Korsching, H., Phys. Zeits., 42, 74 (1941).

20) Lamar, E. S., Buechner, T. W. and Van de Graaff, R. J.,

J. Appl. Phys., 12, 132 (1941). 
(21) Livingeton, M. S., Rev. Mod. Phys., 18, 293 (1946).

(22) Livingston, M. S., Holloway, M. G. and Baker, C. P., R. S. I 10, 63 (1939).

(23) Lorrain, P., Unpublished report PD-158, "A Cold Cathode Discharge for Use in an Ion Source", National Research Council of Canada, 1945.

(24) Luhr, 0., Phys. Rev., 44, 459 (1933).

(25) Massey, H. S. W. and Mohr, C. B. O., Proc. Roy. Soc., A, $\underline{135}, 258$ (1932).

(26) Maxwell, L. R., R. S. I., a, 129 (1931).

(27) Newhall, H. F., Phys. Rev., 62, 11 (1942).

(28) Penning, F. M., Physica III, 873 (1936).

(29) Penning, F. M., Physica IV, 71 (1937).

(30) Penning, F. M. and Moubis, J. H. A., Physica IV, 1190 (1937).

(31) Ritschl, V. R., Phys, Zeits, 38, 141 (1937) (107 references).

(32) Scott, G. W. , Jr., Phys. Rev., 55, 954 (1939).

(33) Seeliger, R., "Physik der Gasentladungen".

(34) Smith, L. P. and Scott, G. W., Jr., Phys. Rev., 55, 946 (1939

(35) Smyth, H. D., Phys. Rev., 25, 452 (1925).

(36) Smyth, H. D., Rev. Mod. Phys., 3 , 347 (1931).

(37) Steacie, E. W. R., "Atomic and Free Radical Reactions", 1946. (38) Thoneman, P. C., Nature, 158, 61 (1946).

(39) von Ardenne, M., Phys. Zeits., 43, 91 (1942).

(40) Von Ardenne, M., Zeits. f. Phys., 121, 236 (1943).

(41) Nalcher, W., Zeits. f. Phys., 122, 62 (1944).

(42) Ward, A. G., Unpublished report PM-148, "Notes on Positive 
Ion Sources", National Research Council of Canada, 1945. (43) Mood, R. T., Proc. Roy. Soc., A, 102, 1 (1922). 
ACC. NOUNACO. ${ }^{\mathrm{REC} D}$ 